\title{
Investigation of infertility with the emphasis on laboratory testing and with reference to radiological imaging
}

\section{Williams, T Giannopoulos, E A Sherriff}

This review will discuss the investigation of infertility, with emphasis on laboratory testing and reference to the value of other investigations, including clinical and radiological. The role of laboratory investigations is viewed within an appropriate clinically directed pathway that includes medical, surgical, and social history together with environmental factors. Because embryology and assisted reproduction techniques are developing rapidly and produce continuous changes in everyday practice, this article gives a critical review of the plethora of tests that are currently used.

See end of article for authors' affiliations

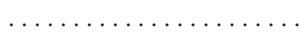

Correspondence to Dr T Giannopoulos, Assisted Conception Unit, St Helier Hospital, Wrythe Lane, Carshalton, Surrey SM5 1AA, UK. tgiuk@yahoo.co.uk

Accepted for publication 11 November 2002 nfertility affects one in seven couples in the UK
and a typical district health authority may see
around 230 new consultant referrals each year,
but there is a wide variation in management. ${ }^{.}$The
1995 National Survey of Family Growth in the
United States noted that $10 \%$ of women aged
15-44 years reported some form of "fecundity
impairment" and $44 \%$ of these women sought
medical help.

\section{DEFINITION OF SUBFERTILITY}

The definition of infertility varies considerably, particularly in relation to the length of time of regular unprotected intercourse. Most practitioners would start investigations if the woman does not conceive after a period of one year. However, individual circumstances will differ and couples should generally be seen whenever they think there is a problem. Often, there are other factors such as the woman's age (usually more than 37 years), previous surgery, or irregular menstrual cycles that warrant earlier investigation than the usual one year of trying.

\section{ROLES AND LIMITATIONS OF THE LABORATORY}

In developed countries, $22 \%$ of infertility is caused by a male factor alone and in a further $21 \%$ both male and female factors are involved. ${ }^{3}$ In combined data from over 5000 infertile couples, ${ }^{4} 30 \%$ of problems related to ovulation and $22 \%$ to seminal defects. Laboratories potentially contribute to the diagnosis of over $50 \%$ of couples investigated.

\section{ANALYTICAL ISSUES}

Laboratories must ensure that reference ranges, conditions of collection, and specimen preservation are appropriate to their clinical applications. Clinicians may need advice upon the reproducibility of assays and the transferability of assay data from the literature to other sites. Although three luteinising hormone (LH)/follicle stimulating hormone (FSH) assays account for over 70\% of the UK market there are many more in use. Most of the 10 most popular LH and FSH assays in the UK have a geometric coefficient of variation of $10 \%$ or less $s^{5}$ tested within the ovulatory range, but some are systematically better than others. Some LH assays crossreact with human chorionic gonadotrophin, which may be clinically important in the investigation of the amenorrhoeic patient. ${ }^{6}$ The coefficient of variation (CV) profile of most oestradiol assays is not suited to discriminating low values, ${ }^{7}$ with at best an interlaboratory CV of $25 \%$ at $200 \mu \mathrm{mol} /$ litre, increasing exponentially below this value. Clinical samples should be referred to specialist laboratories when precise measurement is required at lower values.

\section{"In combined data from over 5000 infertile couples, $30 \%$ of problems related to ovulation and $22 \%$ to seminal defects"}

Macroprolactinaemia, as a high molecular weight complex of prolactin (PRL), reacts to a variable extent in commercial PRL kit immunoassays, resulting in raised PRL values. Macroprolactin was found to be mainly responsible for raised "prolactin" in one out of four to five sera where values were up to two to three times higher than the top of the reference ranges ${ }^{8-10}$; these observations call into question the derivation of reference ranges themselves. ${ }^{10}$ Allowing for their

\footnotetext{
Abbreviations: $A S A B$, antisperm antibody; $B M I$, body mass index; CMSPT, cervical mucous sperm penetration testing; CV, coefficient of variation; DHEAS, dehydroepiandrosterone sulfate; EQA, external quality assessment; $\mathrm{FSH}$, follicle stimulating hormone; IBT, immunobead testing; ICSI, intracytoplasmic sperm injection; $\mathrm{LH}$, luteinising hormone; MAR, mixed antiglobulin reaction; PCOS, polycystic ovarian syndrome; PRL, prolactin; SHBG, steroid hormone binding globulin; TFT, thyroid function test; WHO, World Health Organisation
} 
lower relative proportions, higher ranges of raised PRL may be equally affected by macroprolactin and there are not enough data to be confident about defining a value at which macroprolactin can be neglected as a possible cause of raised PRL, although evidence indicates that macroprolactin is rarely reported at total PRL > $20000 \mathrm{mU} /$ litre (Dr M Fahie-Wilson, personal communication, 2002). It has been recommended that when total PRL is $>700 \mathrm{mU} /$ litre the sample should be investigated for the presence of macroprolactin, ${ }^{1011}$ and measurement of PRL after treatment with polyethylene glycol, which precipitates macroprolactin, is one way of doing this. Because at this stage the clinical consequences of this entity seem relatively benign, referral and intensive investigation of affected patients may not be necessary; however, follow up of a large cohort in terms of longterm clinical outlook is required (Dr M Fahie-Wilson, personal communication, 2002). ${ }^{12}$ Because macroprolactinaemia does not exclude a pituitary adenoma, perhaps pituitary imaging studies should be ordered in patients with macroprolactinaemia when this is indicated by clinically relevant features. ${ }^{13}$

PRL is susceptible to stress effects and a protocol should be in place to identify this. A small study ${ }^{14}$ and other evidence ${ }^{15}$ suggest that venepuncture does not raise PRL and serial testing at 0,30 , and 60 minutes was reported to identify and exclude stress related hyperprolactinaemia. ${ }^{16}$ PRL stimulation tests and the nocturnal profiling of prolactin probably add little to the differentiation of adenomas from other causes of increased PRL. ${ }^{117}$

LH measurement may exceptionally be affected by a very rare LH $\beta$-subunit variant reducing LH detection. ${ }^{18}$

Analytical services for sperm have been relatively inconsistent in term of the quality of performance in external quality assurance (EQA) programmes and the elements of service provided, but are improving ( $\mathrm{Dr} \mathrm{AD}$ Atkinson, personal communication, 2002). The UK External Quality Assurance Scheme data now indicate that most non-specialist laboratories perform satisfactorily (Dr AD Atkinson, personal communication, 2002).

\section{LIMITS UPON DIRECT INTERPRETATION OF TEST RESULTS}

Significantly abnormal test results do not necessarily preclude successful reproductive function. For instance, fertile and infertile men are not separated by World Health Organisation $(\mathrm{WHO})^{19}$ criteria because pregnancy may occur as long as motile sperm are evident. Some identifiable defect or functional failing relating to sperm occurs in $20 \%$ to $30 \%$ of couples investigated for infertility subject to the criteria used and studies undertaken. Although abnormal semen analysis parameters such as count and percentage of normal forms are reliable indicators of subfertility, some tests such as sperm antibody assays are not..$^{20}$

\section{SALIVA AND STEROID INVESTIGATIONS}

Clinicians may not be aware that clinical sampling using saliva for steroid measurements is practicable in some circumstances, ${ }^{21-36}$ including the measurement of oral progesterone..$^{25}$ In general, however, significant interindividual differences occur in saliva to serum ratios and these have not been investigated under the range of physiological and therapeutic conditions that may disturb them. Few papers share identical methods and it can be assumed that transferability of absolute reported values will be limited. Saliva matrix effects vary significantly between different manufacturers' radioimmunoassay assay $\mathrm{kits}^{37}$ and systematic differences were evident between nine laboratories measuring saliva testosterone in an EQA survey. ${ }^{38}$ Salivary assays should only be considered where relevant analytical and interpretive expertise permits.

\section{THE INVESTIGATION OF THE INFERTILE COUPLE}

There is no evidence that the recommended practice of managing the male and female partner together, as opposed to separately, improves either reproductive outcomes or nonreproductive outcomes, such as acceptance of infertility, or that temperature charts and LH detection methods to time intercourse improve outcome..$^{39}$

\section{INVESTIGATIONS OF THE FEMALE PARTNER \\ Serum progesterone: use as a key test}

Recurring menstrual cycles are usually (95\% confidence ${ }^{41}$ ) ovulatory if they vary by no more than a few days within normal confidence limits of duration and are associated with premenstrual symptoms. However, ovulation should still be confirmed by the measurement of serum progesterone in the midluteal phase.

A value of serum progesterone of $>30 \mathrm{nmol} /$ litre is considered proof of adequate ovulation, although the WHO uses $18 \mathrm{nmol} /$ litre to confirm ovulation (appendix 1). Progesterone values have either been measured in women with regular menstrual cycles that are assumed to be ovulatory or in conception cycles where ovulation must have taken place.

It is important that the sample is timed in relation to the subsequent onset of menses, otherwise interpretation is difficult. A mistimed sample is the most common cause of an abnormal result. The sample should be taken seven days before the expected onset of menses. If a woman has a long or unpredictable cycle the sample may need to be repeated weekly until the next menstrual cycle starts.

\section{Serum prolactin, FSH, LH, thyroid tests, and oestradiol in the broad classification of disorders}

Anovulatory infertility is the most common cause of female infertility, often characterised by irregular menstruation, amenorrhoea, or oligomenorrhoea; however, ovulatory dysfunction may occur coincidentally with apparently regular cycles. Performance of these tests, usually done on day 2-4 of the cycle (if there is one), in concert with clinical observations, will normally identify the four main causes of ovulatory failure, namely: normogonadotrophic anovulation, hyperprolactinaemia, hypogonadotrophic hypogonadism, and hypergonadotrophic hypogonadism. In the absence of periods, greatly raised FSH (> $50 \mathrm{IU} / \mathrm{ml}$ ) is diagnostic of ovarian failure; however, most patients with oligomenorrhoea or amenorrhoea will have normal gonadotrophins as part of the polycystic ovarian syndrome (PCOS). When serum oestrogen is normal, the maximum normal prolactin should be in the range 600$800 \mathrm{mIU} / \mathrm{ml}^{42}$ Raised prolactin may be physiological (such as, pregnancy) or may indicate pituitary prolactinoma, stalk compression by hypothalamic or pituitary tumours, thyroid failure, PCOS, psychotherapeutic medication, or other pathology (table 1$)^{43}$

"Anovulatory infertility is the most common cause of female infertility, often characterised by irregular menstruation, amenorrhoea, or oligomenorrhoea"

Table 1 Causes of hyperprolactinaemia

Physiological (pregnancy, stress, nipple stimulation, coitus) Pituitary prolactinoma

Any pituitary/hypothalamic tumour that compresses the pituitary stalk Idiopathic hypersecretion

Primary hypothyroidism

Pharmacological causes (phenothiazines, butyrophenones, pimozide, cimetidine, methyldopa)

Polycystic ovarian syndrome

Renal/liver failure

Traumatic or neoplastic lesions of the thorax or spine

Ectopic production of prolactin by extrapituitary tumour 
Low LH and FSH concentrations $(<5 \mathrm{mIU} / \mathrm{ml})$, low oestradiol values $(<40 \mathrm{pg} / \mathrm{ml})$, along with a negative gestagen challenge test (no withdrawal bleeding) result from hypogonadotrophic hypogonadism, which is usually a result of primary hypothalamic or pituitary failure. Other causes include excessive stress or exercise, malnutrition, or low weight. Assessment of anterior pituitary function reserve should be undertaken in accordance with local protocols. The precise measurement of low oestradiol concentrations can also be useful in the investigation of precocious puberty and Turner's syndrome.

Currently, the FSH concentration is the favoured marker for assessing ovarian reserve and for predicting the response to superovulation, with a good correlation with pregnancy rates. FSH values are checked on day 2 to day 4 with a cutoff point of 12 IU/litre. Once the FSH concentrations start to fluctuate, there is already a decreased ovarian reserve and it is not clear whether starting stimulation in a later month with "normal" FSH values will give a better result.

Hypergonadotrophic hypogonadism is defined by raised FSH concentrations $(>20 \mathrm{mIU} / \mathrm{ml}$ ) and indicates ovarian failure. In younger women the cause may be idiopathic, iatrogenic, or genetic (for example, Turner's syndrome). In older women, near the end of their reproductive life, a raised FSH concentration is the result of aging of the ovary and therefore indicates imminent menopause. Patients younger than 30 years of age should have a karyotype determination because the incidence of chromosomal abnormalities in this age group with premature ovarian failure is estimated to be $2-5 \%$.

The Royal College of Obstetricians and Gynaecologists recommends that thyroid function tests (TFTs) should be reserved for the particular subset of infertile women with irregular menstrual cycles and for women with signs and/or symptoms of thyroid disease, and PRL measurement for those women with amenorrhoea, oligomenorrhoea, or clinical symptoms of hyperprolactinaemia, such as galactorrhoea. If initial fertility investigations are all normal, it is worth considering TFTs in women with regular cycles to pick up a small proportion of women who may have a diagnosis of subclinical thyroid disease. ${ }^{44}$

\section{Serum testosterone, dehydroepiandrosterone sulfate (DHEAS) and 17-OH progesterone in the determination of androgen excess}

Idiopathic hirsutism is associated with clinical signs of enhanced androgen activity from $5 \alpha$ reductase activity in hair follicles converting normal testosterone to the more androgenic dihydrotestosterone. The major (non-idiopathic) example of androgen excess as a cause of infertility is PCOS, originally described by Stein and Leventhal in 1935. Classically, in PCOS there is a rise in LH, the LH/FSH ratio, and testosterone. The exact aetiology is still a matter of debate, but it is thought that a state of chronic anovulation leads to an androgenic milieu and a chronic rise in basal LH, which further enhances the state of hyperandrogenism, thus starting and maintaining a vicious circle. Commonly, there are multiple small ovarian cysts, thickened ovarian capsule, hirsutism, obesity, raised peripheral insulin values, and increased insulin resistance. The prevalence is $5 \%$ or more in all females subject to problems of definition. The classic view of PCOS still influences laboratory perceptions of PCOS. Ultrasound has limited predictive value for abnormal hormonal results ${ }^{45}$ and no absolute biochemical criteria are in general use. A summary of the predictive relevance of some tests requested is set out below:

- Ultrasound: although body mass index (BMI) exceeds 25 in two thirds of women with PCOS, some are relatively lean and lack the typical polycystic ovaries on transvaginal ultrasound $^{43}{ }^{46}$; precise ultrasonic definition also remains controversial, mainly because of the lack of normative data. ${ }^{47}$

- Gonadotrophins: only one third to a half of those women with a clinical and endocrine picture of PCOS will have raised $\mathrm{LH} / \mathrm{FSH}$ ratios. $\mathrm{LH}$ may be more diagnostic ${ }^{48}$; using ultrasound as a reference test for PCOS, approximately two thirds of women may have raised $\mathrm{LH}^{49}$ and a combination of $\mathrm{LH}, \mathrm{FSH}$, and androstenedione is reported to have a sensitivity and specificity of $98 \%$ and $93 \%$, respectively. ${ }^{50}$

- Testosterone: this hormone is raised in $70 \%$ of more of patients with PCOS. ${ }^{49} 51$

- Androstenedione: approximately half of those women with clinical and ultrasound evidence of PCOS, ${ }^{51}$ up to $74 \%$ in some reports, ${ }^{49}$ have raised androstenedione; however, one report of 150 adolescent girls diagnosed clinically and by ultrasound found that androstenedione was in general normal.

- Sex hormone binding globulin (SHBG): there was a negative correlation between SHBG and BMI in PCOS in one study, but the measurement of SHBG is probably not helpful, either directly or in combination ${ }^{51}$ with other tests. ${ }^{50} 5253$

- DHEAS and oestradiol: there is no evidence of a general role for DHEAS and oestradiol in the positive prediction of PCOS.

- Dynamic tests: LH releasing hormone ${ }^{54}$ test protocols, LH/FSH ratio, insulin plus or minus testosterone, ${ }^{53} \mathrm{LH}$ pulsatility characteristics and amplitude, ${ }^{55}$ free androgen index, progestogen challenge, ${ }^{49}$ and hormone response to buserelin $^{56}$ are of value in specialist practice (progestogen challenge is used to induce withdrawal bleeding in oligomennorhoeic women before starting an in vitro fertilisation (IVF) cycle. The hormone response to buserelin (by measuring FSH values) has been tested as a predictor of ovarian response to superovulation; however, it has not been proved superior to basal FSH in predicting IVF success).

Other causes of this type of ovulatory dysfunction include congenital adrenal hyperplasia, adrenal tumours, and androgen producing ovarian tumours. In all these conditions, testosterone is raised, which should initiate more detailed investigations such as measurement of DHEAS and 17-OH progesterone. After the exclusion of other causes of hyperandrogenism and annovulation, testosterone is probably the single best laboratory marker of PCOS..$^{51} 57$

\section{Microbiological investigations}

Susceptibility to infection among women with a history of rubella immunisation suggests that the seroconversion rate in clinical practice may be lower than in vaccine trials; rubella immunological status should therefore be established before initiating active fertility management. General investigative tests may also include syphilis serology, hepatitis B and C virus antibodies, and human immunodeficiency virus serology.

\section{The postcoital test}

Cervical mucous is collected 8-12 hours after coitus and the number of progressively motile sperm in each high field power is recorded, with five usually taken as the lower limit of normal. Unfortunately, this is not a very discriminatory test and it also has poor reproducibility and wide interobserver variation. ${ }^{58}$

\section{Ultrasound examination}

Ultrasound is a key test in PCOS and other ovarian pathology. Decreased ovarian volume is a sign of ovarian aging that may be seen earlier than a rise in FSH concentrations. Ultrasound can also be used to evaluate the uterine cavity for pathology that can compromise fertility, such as submucosal fibroids or septa. Its accuracy can be further enhanced by the instillation of saline into the uterine cavity, to act as a contrast medium. Ultrasound of the endometrium is not of confirmed value in the initial investigation of infertility. 


\section{Endometrial biopsy}

As a way of evaluating the luteal phase, endometrial biopsy is not of confirmed value as a routine investigation.

\section{Hysterosalpingogram, laparoscopy, and hysterosalpingo contrast}

Hysterosalpingography (HSG) and laparoscopy with chromopertubation are not mutually exclusive because apart from testing tubal patency they provide different information. The procedure of choice is determined by the clinical circumstances of both partners. Hysterosalpingography gives information about the uterine cavity that a laparoscopy and dye test cannot provide (unless combined with hysteroscopy), whereas laparoscopy gives information about the rest of the pelvis, including peritubal adhesions, endometriosis, and ovarian pathology. Laparoscopy has a $1-2 \%$ complication rate $^{59}$ and a mortality rate of eight in 100000 . A hysterosalpingogram may be used as a screening test for tubal patency in low risk couples. However, when an evaluation of the pelvis is required a diagnostic laparoscopy with dye transit is the procedure of choice. Those with risk factors for pelvic or tubal disease or an abnormal pelvic examination should proceed directly to laparoscopy because they are more likely to have pelvic pathology. Hysterosalpingo contrast sonography is increasingly used as a test for tubal patency.

\section{INVESTIGATIONS OF THE MALE PARTNER}

Male parenting cannot be taken as evidence of sperm quality. Subject to socioeconomic, regional, and international weighting factors, $1 \%$ to $30 \%$ of children cannot be genetically matched to their presumptive fathers. ${ }^{60}$ Although reliable authenticated data on non-paternity rates are sparse it seems probable that the UK rate lies close to $1 \%{ }^{61-63}$

\section{Semen analysis}

Evaluation of sperm morphology continues to cause problems for many people, ${ }^{64}$ reflecting internal and external quality assurance and training issues under active consideration (Dr $\mathrm{AD}$ Atkinson, personal communication). Laboratories should perform semen analysis according to recognised WHO methodology $^{19}$ and subscribe to the appropriate EQA scheme. ${ }^{65}$ Two sperm samples are suggested, 10 to 12 weeks apart. The laboratory should receive the samples within one hour of production. Men should be referred to a specialist infertility clinic if the results of either of their semen analyses fall below WHO criteria (table 2). These standards form a basis for referral but are not necessarily a guide to ultimate fertility. Wide intraindividual variation in sperm counts ${ }^{19}$ are relevant

Table 2 Suggested protocols for semen collection and World Health Organisation (WHO) normal values

Collection of a semen sample

Abstain for two to three days

Produce the sample by masturbation, not by coitus interruptus Do not use condoms for collection of the sample or lubricant jellies Use a wide mouth sterile plastic specimen pot to collect the sample Mark the container clearly with the name, date and time of production, and the date of the immediate preceding ejaculation by coitus or masturbation

Deliver to the laboratory as quickly as possible

Protect the sample from extremes of temperature $\left(<15^{\circ} \mathrm{C}\right.$ or $\left.>38^{\circ} \mathrm{C}\right)$

during transport-do not keep at body temperature

WHO values ${ }^{21}$ for "normal" semen analysis include

Volume $2 \mathrm{ml}$ or more

Concentration, 20 million/ml or more

Motility, $50 \%$ progressive motility or more

Morphology, $15 \%$ or more normal forms

White blood cells, $<1$ million $/ \mathrm{ml}$ to individual assessment. Data suggest that as sperm morphology drops below 15\% the success of normal fertilisation in vitro declines. ${ }^{19}$

\section{"Laboratories should perform semen analysis according to recognised World Health Organisation methodology and subscribe to the appropriate external quality assurance scheme"}

Azoospermia may be the result of a variety of factors. A karyotype is required to exclude intrinsic testicular failure. Ninety per cent of azoospermic patients with chromosomal abnormalities have Klinefelter's syndrome. ${ }^{66}$ Testicular failure may also be the result of hormone abnormalities such as hypogonadotrophic hypogonadism and hyperprolactinaemia or testicular damage (that is, maldescent, mumps). Obstruction (intratesticular, epididymal, vasal, or of the ejaculatory duct) is the other major category and, depending on the site and the duration, surgical treatment could be considered. Transrectal ultrasound can locate the site of the blockage. Plasma FSH is useful in distinguishing primary from secondary testicular failure and in identifying patients with obstructive azoospermia. It has decreased the need for testicular biopsy, which is now largely reserved for confirming normal spermatogenesis in cases of genital tract obstruction. Testosterone and LH measurement are indicated when androgen deficiency, sex steroid abuse, or steroid secreting tumours are suspected. Urinalysis is useful to isolate viable sperm in retrograde ejaculation

\section{Sperm function tests}

None of these tests has been shown to perform well in isolation. However, it is possible that a combination of these tests may be better at predicting fertilisation. The advent of intracytoplasmic sperm injection (ICSI), which overcomes defects in fertilising ability, may have made such tests less relevant to eventual pregnancy outcome. ${ }^{67}$

\section{Computer assisted seminal analysis (CASA)}

The software in use measures the amplitude, frequency, and velocity of spermatozoa, but as yet has no confirmed value in predicting fertilisation potential and is subject to sampling variation.

\section{Hypo-osmotic swelling assay}

This tests the functional integrity of the plasma membrane of the spermatozoa by observing curling of the tail under hypoosmotic conditions. Neither alone or in combination with traditional semen characteristics has it proved to be of value in predicting pregnancy outcome. ${ }^{68}$

\section{Sperm penetration tests}

There is wide disagreement about the outcome of cervical mucous sperm penetration testing (CMSPT) and its association with fertilisation potential. In an attempt to overcome some of the difficulties with in vivo testing, as typified by postcoital tests and CMSPT, attempts have been made to replace human ovulatory cervical mucous with hyaluronic acid polymers or bovine cervical mucous. However, these tests only seem to reflect sperm motility and do not give added information about fertilisation potential.

\section{Hemizona assay}

The ability of spermatozoa to bind to the zona pellucida may be tested in ova stored in a high salt solution. Because zona binding is dependent on oocyte maturity, the oocyte is divided in half with a micropipette so that each half acts as its own control with a fertile sample. This test does have some correlation with fertilising potential but false positive hemizona 
assay results can occur because the fertilisation defect may be in functional steps beyond the tight binding of the sperm to the zona pellucida.

\section{Hamster oocyte penetration assay}

There is a lack of standardisation in this laboratory technique. Longterm follow up (up to 68 months) of couples who have had a hamster egg penetration assay performed has shown no significant difference in the rate or incidence of pregnancy in relation to the results of this test, as analysed by life table analysis. Most studies have been difficult to interpret because of the lack of consensus arising from quality assurance issues.

\section{Biochemical aspects of sperm function}

Acrosin is one of the enzymes present in the acrosome. Its activity has been reported to be greater in fertile than in infertile males; however, there are no prospective evaluations correlating acrosin activity with fertilisation rates in patients undergoing assisted reproduction techniques. The measurement of the production of reactive oxygen species released by spermatozoa may be used as an indicator of sperm function, ${ }^{69}$ but at present this is still a research tool. None of these tests has been shown to perform well in isolation. It is possible, however, that a combination of these tests may be better at predicting fertilisation, although the advent of ICSI, which overcomes defects in fertilising ability, may have made such tests less relevant to eventual pregnancy outcome.

\section{Immunological investigations}

In the infertile population as a whole, antisperm antibodies (ASAB) occurs in 5-10\% of individuals (men more than women $){ }^{70}$ but they are also present in about $2 \%$ of fertile men, most commonly IgG and IgA. IgM antibodies, because of their size, are rarely found in semen and if present may be associated with infection. Sperm bound IgA antibodies are associated with poor cervical mucous penetration, but this is not the case with sperm bound IgG antibodies. The presence of sperm antibody in the serum of either partner is probably associated with impaired fertility, but the case has not been proved, so that routine testing for serum ASAB, although widely practised, is not recommended. Immunobead testing (IBT), however, against IgA and IgG in semen is recommended, although differences in analytical practice render comparisons of test results between centres unreliable. Assays that only identify serum ASAB may not be optimal because antibodies in the male genital tract may be of primary importance.

Semen screening for antibodies is performed on fresh samples and makes use of either the IBT method or the mixed antiglobulin reaction (MAR) test. The sample must contain at least 100 spermatozoa with progressive motility and the mucous, debris, and bacteria content must not be so high as to interfere with these tests. ${ }^{71}$

\section{The mixed antiglobulin reaction test}

There is no gold standard for the diagnosis of immunological infertility but the MAR test is probably the first method of choice. This test identifies IgG on the spermatozoa. This is considered to be an adequate routine screening test because IgA antibodies almost never occur without IgG antibodies. ${ }^{72}$ Severely oligozoospermic and/or samples with greatly reduced motility are unsuitable for testing. The test is considered positive if $50 \%$ or more sperm have blood cells attached and weakly positive if $10-50 \%$ of the sperm have blood cells attached. In a negative test the sperm should swim freely between the aggregation of red cells. If the red cells do not aggregate together then the test is invalid and should be repeated. The test is considered of clinical relevance when $>50 \%$ agglutination is present.

\section{Take home messages}

- Infertility affects one in seven couples in the UK, but there is a wide variation in management

- In developed countries, $22 \%$ of infertility is caused by a male factor alone and in a further $21 \%$ both male and female factors are involved. Laboratories potentially contribute to the diagnosis of over $50 \%$ of couples investigated

- Laboratories must ensure that reference ranges, conditions of collection, and specimen preservation are appropriate to their clinical applications. Clinicians may need advice upon the reproducibility of assays and the transferability of assay data from the literature to other sites

- Serum progesterone is used as a key test. Prolactin is susceptible to stress effects and macroforms, and a protocol should be in place to identify this

- The results of serum prolactin, follicle stimulating hormone, luteinising hormone, thyroid tests, and oestradiol, together with clinical observations, will normally identify the four main causes of ovulatory failure. However, even significantly abnormal test results do not necessarily preclude successful reproductive function

The immunobead test

The IBT is one of the most widely used tests to detect ASAB, directly on sperm or indirectly in seminal plasma, cervical mucous, follicular fluid, and serum. The presence of IgG, IgA, and IgM antibodies on the sperm surface can be assessed simultaneously with this test. The test is considered to be positive when $20 \%$ or more of motile spermatozoa have immunobead binding, but only clinically relevant when $50 \%$ or more of the motile spermatozoa have antibody bound to them. ${ }^{73}$

\section{Other investigations}

Karyotyping allows detection of problems such as Klinefelter's syndrome (47, XXY), which accounts for many men presenting with non-obstructive azoospermia. Testing for cystic fibrosis carriers in both partners is now considered essential before couples are treated by ICSI if the man has congenital bilateral absence of the vas deferens. Reduced testosterone and raised LH concentrations are indicative of Leydig cell dysfunction. Additional investigations include a urinalysis, a urethral swab for chlamydia, and in some cases scrotal or transrectal ultrasound. Readers are referred to specialist texts ${ }^{74}$ for information on chromosomal investigations.

\section{GOOD PRACTICE FRAMEWORK}

Because reproductive potential is affected by age, pregnancy history, and medical, surgical, social, and environmental factors, laboratory investigations should take place within an appropriate clinically directed pathway. The general practitioner may play a central role in this pathway, with advice and referral to fertility specialists when indicated, because interpretation of the meaning of the various tests may sometimes be outside of his or her field of expertise.

\section{APPENDIX 1 SUGGESTED PROTOCOL FOR ASSESSMENT OF SERUM PROGESTERONE}

Measure serum progesterone seven days before expected period in all women. Interpret after next menstrual period known.

- $<16 \mathrm{nmol} /$ litre, repeat in another cycle. If consistently low refer to specialist.

- > $16 \mathrm{nmol} /$ litre but $<30 \mathrm{nmol} / \mathrm{litre}$, repeat in another cycle. If the same or lower, may be indication for controlled ovarian stimulation so needs referral to specialist.

- > $30 \mathrm{nmol} /$ litre, consider as proof of adequate ovulation. 


\section{ACKNOWLEDGEMENTS}

Thanks to Dr GF Read, University Hospital of Wales, Cardiff, for help and advice.

\section{Authors' affiliations}

C Williams, T Giannopoulos, E A Sherriff, Assisted Conception Unit,

St Helier Hospital, Wrythe Lane, Carshalton, Surrey SM5 IAA, UK

\section{REFERENCES}

1 Templeton A, Fraser C, Thompson B. Infertility-epidemiology and referral practice. Hum Reprod 1991:6:1391-4.

2 Van Voorhis BJ, Stovall DW, Allen BD, et al. Cost-effective treatment of the infertile couple. Fertil Steril 1998;70:995-1005.

3 Effective Health Care. Implementing clinical practice guidelines: can guidelines be used to improve clinical practice? Effective Health Care Bulletin 1994;8. London: Royal Society of Medicine Press.

4 Taylor PJ, Collins JA. Unexplained infertility. Oxford: Oxford University Press, 1902

5 Seth J, Sturgeon CM, Ellis AR, et al. United Kingdom External Quality Assessment Scheme (NEQAS) for Peptide Hormones and Related Substances. Annual review 2000. Department of Clinical Biochemistry, Royal Infirmary, Edinburgh EH3 9YW, UK.

6 Seth J, Sturgeon CM, Ellis AR, et al. United Kingdom External Quality Assessment Scheme (NEQAS) for Peptide Hormones and Related Substances. Annual review 1997. Department of Clinical Biochemistry, Royal Infirmary, Edinburgh EH3 9YW, UK.

7 Thomas A. Wales External Quality Assessment Scheme (WEQAS) Endocrine Scheme. Annual report 1999. Quality Laboratory, Directorate of Pathology, University Hospital of Wales, Heath Park, Cardiff CF4 4 XW, UK

8 Bioro T, Morkrid L, Wergeland R, et al. Frequency of hyperprolactinaemia due to large molecular weight prolactin (150-170 kD PRL). Scand J Clin Lab Invest 1995;55:139-47.

9 Soong YK, Ferguson KM, McGarrick G, et al. Size heterogeneity of immunoreactive prolactin in hyperprolactinaemia serum. Clin Endocrinol 1982;16:256-65.

10 Fahie-Wilson MN, Soule SG. Macroprolactinaemia: contribution of hyperprolactinaemia in a district general hospital and evaluation of a screening test based on precipitation with polyethylene glycol. Ann Clin Biochem 1997; 34:252-8

11 Klockenbush W, Distler W, von Ditfurth $M$, et al. The value of functiona tests in diagnosis of prolactinoma. Geburtshilfe Fravenheilkd 1990;50:383-7

12 Leslie H, Courtney $\mathrm{CH}$, Bell PM, et al. Laboratory and clinical experience in 55 patients with macroprolactinaemia identified by a simple polyethylene glycol precipitation method. J Endocrinol Metab 2001;86:2743-6.

13 Hauache OM, Rochat AJ, Maia ACM, et al. Screening for macroprolactinaemia and pituitary imaging studies. Clin Endocrinol 2002;57:327-31.

14 Ferriani RA, Silva de Sa MF. Effect of venipuncture stress on plasma prolactin levels. Int J Gynaecol Obstet 1985;23:459-62.

15 Ishay A, Luboghitzky R. Diagnosis of hyperprolactinemia: determination of prolactin level at rest. Harefuah 1998;135:348-50, 408, 407.

16 Muneyyirci-Delale O, Goldstein D, Reyes FI. Diagnosis of stress-related hyperprolactinemia. Evaluation of the hyperprolactinemia rest test. $N Y$ State J Med 1989:89:205-8.

17 Pereira MC, Sobrinho LG, Afonso AM, et al. Is idiopathic hyperprolactinemia a transient stage towards prolactinoma? Obstet Gynecol 1987;70:305-8

18 Kurioka H, Takahashi K, Irikoma M, et al. Diagnostic difficulty in polycystic ovary syndrome due to an LH-beta-subunit variant. Eur J Endocrinol 1999;140:235-8.

19 World Health Organization. WHO laboratory manual for the examination of human semen and sperm-cervical mucus interaction. Cambridge: Cambridge University Press, 1999

20 Kremer J, Jager $\mathrm{S}$. The significance of antisperm antibodies for sperm-cervical mucus interaction. Hum Reprod 1992;7:781-4

21 Hughes IA, Read GF. Simultaneous plasma and salivary steroid measurements as an index of control in congenital adrenal hyperplasia (CAH). A longitudinal study. Horm Res 1982;16:142-50.

22 Ohtaki T, Moriyoshi M, Nakada K, et al. Radioimmunoassay of saliva estrone sulfate in pregnant sows. J Vet Med Sci 1997;59:759-63

23 Mounib N, Sultan C, Bringer J, et al. Correlations between free plasma estradiol and estrogens determined by bioluminescence in saliva, plasma and urine during spontaneous and FSH stimulated cycles in women. J Steroid Biochem 1998;31:861-5.

24 Gaskell SJ, Finlay EM, Pike AW. Analyses of steroids in saliva using highly selective mass spectrometric techniques. Biomed Mass Spectrom 1980;7:500-4.

25 Bolaji II, Tallon DF, O'Dwyer E, et al. Assessment of bioavailability of oral micronized progesterone using a salivary progesterone enzymeimmunoassay. Gynecol Endocrinol 1993;7:101-10.

26 Swinkels $\mathbf{L M}$, van Hoof HJ, Ross $\mathrm{HA}$, et al. Low ratio of androstenedione to testosterone in plasma and saliva of hirsute women. Clin Chem 1992;38:1819-23.
27 Lac G, Lac N, Robert A. Steroid assays in saliva: a method to detect plasmatic contaminations. Arch Int Physiol Biochim Biophys 1993;101:257-62

28 Filaire $E$, Lac G. Dehydroepiandrosterone (DHEA) rather than testosterone shows saliva androgen responses to exercise in elite female handball players. Int J Sports Med 2000;21:17-20.

29 Vining RF, McGinley RA. Hormones in saliva. Crit Rev Clin Lab Sci 1986;23:95-146.

30 Vining RF, McGinley RA. The measurement of hormones in saliva possibilities and piffalls. J Steroid Biochem 1987;27:81-94.

31 Walker RF, Read GF, Wilson DW, et al. Chronobiology in laboratory medicine; principles and clinical applications illustrated from measurements of neutral steroids in saliva. Prog Clin Biol Res 1990;341 A: 105-17.

32 Smith RG, Besch PK, Dill B, et al. Saliva as a matrix for measuring free androgens: comparison with serum androgens in polycystic ovarian disease. Fertil Steril 1979:31:513-17.

33 Seinkels LM, van Hoof HJ, Ross HA, et al. Concentrations of salivary testosterone and plasma total, non-sex-hormone-binding globulin-bound, and free testosterone in normal and hirsute women during administration of dexamethasone/synthetic corticotropin. Clin Chem 1991;37:139-40.

34 Swinkels LM, van Hoof HJ, Ross HA, et al. Low ratio of androstenedione to testosterone in plasma and saliva of hirsute women. Clin Chem 1992;38: 1819-23

35 Tschop M, Behre HM, Nieschlag E, et al. A time-resolved fluorescence immunoassay for the measurement of testosterone in saliva: monitoring of testosterone replacement therapy with testosterone buciclate. Clin Chem Lab Med 1998;36:223-30.

36 Riad-Fahmy D, Read GF, Walker RF. Salivary steroid assays for assessing variation in endocrine activity. J Steroid Biochem 1983:19:265-72

37 Fulton A, Chan S, Coleman G. Effect of salivary proteins on binding curves of three radioimmunoassay kits: Amerlex-M progesterone, Amerlex cortisol, and Biodata testosterone. Clin Chem 1989;35:641-4.

38 Dabbs JM, Campbell BC, Gladue BA, et al. Reliability of salivary testosterone measurements: a multicenter evaluation. Clin Chem 1995:41:1581-4

39 Royal College of Obstetricians and Gynaecologists. Infertility-guidelines for practice. London: RCOG Press, 1992.

40 Rowe PJ, Comhaire FH, Hargreave TB, et al. WHO manual for the standardised investigation and diagnosis of the infertile couple. Cambridge: Cambridge University Press, 1993.

41 Speroff L, Glass RH, Kase N. Regulation of the menstrual cycle. In: Clinical gynecologic endocrinology and fertility, 5th ed. Baltimore: Williams \& Wilkins 1994:809.

42 Speroff L, Glass H, Kase G. Clinical gynecologic endocrinology and infertility, 5th ed. Baltimore: Williams \& Wilkins, 1994

43 Illions EH, Valley MT, Kaunitz AM. Infertility: a clinical guide for the internist. Womens Health Issues, Part II 1998;82.

44 Arojoki $M$, Jokimaa $V$, Juuti $A$, et al. Hypothyroidism among infertile women in Finland. Gynecol Endocrinol 2000;14:127-31.

45 Van Santbrink EJ, Hop WC, Fauser BC. Classification of normogonadotropic infertility: polycystic ovaries diagnosed by ultrasound versus endocrine characteristics of polycystic ovary syndrome. Fertil Steril 1997;67:452-8

46 Dramusic V, Goh VH, Rajan U, et al. Clinical, endocrinologic, and ultrasonographic features of polycystic ovary syndrome in Singaporean adolescents. J Pediatr Adolesc Gynecol 1997;10:125-32.

47 Dewailly D. Definition and significance of polycystic ovaries. Baillieres Clin Obstet Gynaecol 1997;11:349-68.

48 Fauser BC, Pache TD, Hop WC, et al. The significance of a single serum LH measurement in women with cycle disturbances: discrepancies between immunoreactive and bioactive hormone estimates. Clin Endocrinol 1992;37:445-52.

49 Fox $\mathbf{R}$, Corrigan E, Thomas PA, et al. The diagnosis of polycystic ovaries in women with oligo-amenorrhoea: predictive power of endocrine tests. Clin Endocrinol 1991;34:127-31.

50 Koskinen P, Penttila TA, Anttila L, et al. Optimal use of hormone determinations in the biochemical diagnosis of the polycystic ovary syndrome. Fertil Steril 1996:65:517-22.

51 Robinson S, Rodin DA, Deacon A, et al. Which hormone tests for the diagnosis of polycystic ovary syndrome? Br J Obstet Gynaecol 1992;99:232-8

52 Montalto J, Funder JW, Yong AB, et al. Serum 5-androstene-3 beta, 17 beta-diol sulphate and 5 alpha-androstane-3 alpha, 17 beta-diol sulphate in hirsute females with polycystic ovarian disease. J Steroid Biochem 1990;36:67-74

53 Turhan NO, Toppare MF, Seckin NC, et al. The predictive power of endocrine tests for the diagnosis of polycystic ovaries in women with oligoamenorrhea. Gynecol Obstet lnvest 1999;48:183-6.

54 Oppermann K, Cho MM, Spritzer PM. Serum levels in hirsute anovulatory women. Braz J Med Biol Res 1993;26:799-803

55 Collet C, Lecomte P, Guilloteau D, et al. Luteinizing hormone measurement in polycystic ovary syndrome: a practical approach. Eur J Endocrinol 1999;141:225-30.

56 Hagag P, Ben-Shlomo A, Herzianu I, et al. Diagnosis of polycystic ovary disease in obese women with a 24 hour hormone profile after buserelin stimulation. J Reprod Med 2000;45:171-8.

57 Gandar R, Spizzo M, Collin D. Diagnosis and treatment of polycystic ovary syndrome. J Gynecol Obstet Biol Reprod (Paris) 1999;28:510-18.

58 Irvine OS, Aitken RJ. Seminal fluid analysis and sperm function testing. Endocr Metab Clin North Am 1994;23:725-48. 
59 Chamberlain G, Brown JC. Gynaecological laparoscopy-the report of the working party of the confidential enquiry into gynaecological laparoscopy. London: RCOG Press, 1978.

60 Cerda-Flores RM, Barton SA, Marty-Gonzalez LF, et al. Estimation of nonpaternity in the Mexican population of Nuevo Leon: a validation study with blood group markers. Am J Phys Anthopol 1999:109:281study

61 Macintyre S, Sooman A. Non-paternity and prenatal genetic screening Lancet 1991;338:869-71.

62 Brock DGH, Shrimpton AE. Non-paternity and prenatal genetic screening. Lancet 1991;338:1151.

63 Sykes B, Irven C. Surnames and the Y chromosome. Am J Hum Genet 2000;66:1417-19

64 Atkinson AD. United Kingdom External Control Assessment Scheme. Annual Report 1999-2000. Sub-Fetiltity Laboratory, St Mary's Hospital, Hathersage Road, Manchester, M13 OJH.

65 United Kingdom External Control Assessment Scheme. Sub-Fetiltity Laboratory, St Mary's Hospital, Hathersage Road, Manchester, M13 $\mathrm{OJH}$.

66 Chandley AC. The chromosomal basis of human infertility. BM 1979:35:181-6.
67 The management of infertility in secondary care. Evidence based guidelines no 3. Royal London: College of Obstetricians and Gynaecologists, February 1998.

68 Barratt CLR, McLeod IO, Ounphy B, et al. Prognostic value of two putative sperm function tests: hypo-osmotic swelling and bovine sperm mucus penetration test (Penetrak). Hum Reprod 1992; 7: 1240-4.

69 Aitken RJ, Irvine DS, Wu FC. Prospective analysis of sperm-oocyte fusion and reactive oxygen species generation as a criteria for the diagnosis of fertility. Am J Obstet Gynecol 1991;164:542-51.

70 Matson PL. Detection and clinical significance of sperm antibodies. In: Grudzinskas JG, Yovich JL, Chard T, eds. Cambridge reviews in human reproduction. Cambridge: Cambridge University Press, 1994.

71 The initial management and investigations of the infertile couple. Evidence based guidelines no 2. London: Royal College of Obstetricians and Gynaecologists, February 1998

72 Haas GGJ. Antisperm antibodies in infertile men. J Am Med Assoc 1996;275:885-6.

73 Clarke GN, Elliott PJ, Smaila C. Detection of sperm antibodies in semen using the Immunobead test: a survey of 813 consecutive patients. Am J Reprod Immunol Microbiol 1985;7:1 18-23.

74 The management of infertility in tertiary care. Evidence based guidelines no 6. Royal London: College of Obstetricians and Gynaecologists, January 2000.

\section{V $\delta 2$ cells depleted in both tuberculosis and HIV}

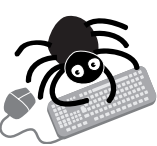

Please visit the Journal of

Clinical

Pathology website [www. jclinpath.com] for link to this full article. subset of circulating $\gamma \delta \mathrm{T}$ cell- $\mathrm{V} \delta$-is depleted in both tuberculosis and HIV infections, $\triangle$ irrespective of whether TB is active and whether the diseases are concurrent, Italian researchers have discovered.

Recent studies have suggested that $\gamma \delta$ T lymphocytes have an important role in the immune response to Mycobacterium tuberculosis, but that the strength of the response varies according to the phase of infection and the immune status of the host.

$\mathrm{CD} 4+, \mathrm{CD} 8+$ and $\mathrm{V} \delta 1$ and $\mathrm{V} \delta 2 \mathrm{~T}$ cell counts were analysed in the peripheral blood of 74 consecutive patients with TB, 20 of whom were co-infected with HIV. The results were compared with those from 39 blood donors and nine patients with symptomless HIV infection. The numbers of total lymphocytes and CD4+ cells were lower in the $54 \mathrm{~TB}$ patients not co-infected with HIV than in blood donors. But total $\gamma \delta \mathrm{T}$ cells and V $\delta 1$ subsets were similar in both groups.

However, the percentage $\gamma \delta \mathrm{T}$ cells with the $\mathrm{V} \delta 2$ subset was significantly lower in TB patients than in either blood donors or patients with symptomless HIV infection. Responsiveness to the tuberculin skin test did not influence which $\gamma \delta \mathrm{T}$ cell subset predominated. The percentage of circulating V $\delta 2$ cells was also lower in HIV positive patients, whether or not their TB was active, and comparable with levels in HIV negative patients.

The finding prompts the authors to ask whether the depletion of $V \delta 2 \mathrm{~T}$ cells might be explained by a pathological mechanism that is common to both infections.

A Thorax 2002: 57:357-360. 


\section{CORRESPONDENCE}

If you have a burning desire to respond to a paper published in Journal of Clinical Pathology, why not make use of our "rapid response" option?

Log on to our website (www.jclinpath.com), find the paper that interests you, and send your response via email by clicking on the "eletters" option in the box at the top right hand corner.

Providing it isn't libellous or obscene, it will be posted within seven days. You can retrieve it by clicking on "read eletters" on our homepage.

The editors will decide as before whether to also publish it in a future paper issue.

\section{Optimal detection of Campylobacter spp in stools}

In view of the importance of Campylobacter spp and related organisms in human disease, and the awareness of the under-reporting of these organisms from stools, we read with interes the recent reports of McClurg and associates and of Kulkarni et al. ${ }^{2}$ These two studies independently compared the recovery of campylobacter and related species from human stools using non-selective filtration, selective plating, and polymerase chain reaction (PCR) detection.

Since 1977, the Red Cross Children's Hospital in Cape Town, South Africa, has been isolating Campylobacter spp. In 1990, for cost containment reasons, the use of antibiotic containing selective media was discontinued, and the "Cape Town" protocol introduced. This protocol $^{34}$ combines both membrane filtration on to antibiotic free blood agar plates and incubation in an $\mathrm{H}_{2}$ enriched microaerobic atmosphere (Oxoid BR 38 (Oxoid, Basingstoke, UK) or BBL 70304 without catalyst (BBL, Kansas City, USA)). Although other workers have advocated filtration for isolation, the Cape Town protocol is the first to combine filtration with a hydrogen enhanced microaerophilic growth atmosphere.

The use of antibiotic free plates allows the growth of antibiotic sensitive campylobacte strains, and the increased $\mathrm{H}_{2}$ in the incubation atmosphere permits the growth of species with an essential requirement for $\mathrm{H}_{2}$ such as $C$ concisus and $C$ rectus. Some strains of $C$ jejuni subspecies jejuni, $C$ jejuni subspecies doylei, and $C$ upsaliensis grow poorly, or not at all, under conventional microaerobic conditions, but will flourish in an $\mathrm{H}_{2}$ enhanced microaerobic atmosphere. ${ }^{35}$ Incubation in an $\mathrm{H}_{2}$ enhanced microaerobic atmosphere increased stool cultures positive for campylobacter by $78 \% \mathrm{com}$ pared with stools incubated under conventional microaerobic conditions. ${ }^{3}$ McClung and colleagues $^{1}$ and Kulkarniand colleagues described their growth conditions as microaerobic $^{1}$ or microaerophilic ${ }^{2}$ without stating the hydrogen concentration. These laboratories experienced overgrowth of the membrane filters by commensal faecal flora, ${ }^{2}$ and used membrane filters with a pore size of $0.45 \mu \mathrm{m} .{ }^{2}$ We have found filters with a pore size of $0.60 \mu \mathrm{m}$ to be optimal for the Cape Town protocol (unpublished results, 1990). These factors may have contributed to the isolation of fewer campylobacter strains. ${ }^{12}$

We agree that PCR diagnosis of campylobacter in stools is not practical for diagnostic laboratories, ${ }^{2}$ especially those in developing countries. We also agree that it may not be cost effective to use several selective media and/or filtration for efficient enteropathogenic campylobacter isolation. ${ }^{1}$ For the past 12 years we have efficiently isolated and biochemically speciated hundreds of strains each year of 17 species or subspecies of campylobacter, arcobacter, and helicobacter from the diarrhoetic stools and blood cultures of our patients, without selective media, but with the use of the Cape Town protocol. ${ }^{3-5}$ When tested against a variety of selective media, the Cape Town protocol was consistently superior for the isolation of campylobacteraceae. ${ }^{3-5}$ Differences in the prevalence of campylobacter may well exist between Cape Town and the UK, and the application of the Cape Town protocol in future UK studies, as has been suggested, ${ }^{2}$ should improve the campylobacter isolation rate and, hopefully, answer this question.

A J Lastovica, E Le Roux Departments of Medical Microbiology, University of Cape Town and Red Cross Children's Hospital

Cape Town, South Africa; lastovic@curie.uct.ac.zo

\section{References}

McClurg KR, McClurg RB, Moore JE. Efficient isolation of campylobacters from stools: what are we missing? J Clin Pathol 2002;55:239-40.

2 Kulkarni SP, Lever S, Logan JM, et al. Detection of campylobacter species: a comparison of culture and polymerase chain reaction based methods. J Clin Pathol 2002; 55:749-53

3 Le Roux E, Lastovica AJ. The Cape Town protocol: how to isolate the most campylobacters for your dollar, pound, franc, yen, etc. In: Lastovica AV, Newell DE, Lastovica EE, eds. Campylobacter, Helicobacter, and related organisms. Cape Town: University of Cape Town, 1998:30-3.

4 Lastovica AJ, Le Roux E. Efficient isolation of campylobacteria from stools. J Clin Microbiol 2000:38:2798-9.

5 Lastovica AJ, Le Roux, E. Efficient isolation of Campylobacter upsaliensis from stools. J Clin Microbiol 2001:39:4222-3.

\section{CORRECTION}

Investigation of infertility with the emphasis on laboratory testing and with reference to radiological imaging. Williams C, Giannopoulos T, Sherriff EA. J Clin Pathol 2003;56:261-7.

Dr C Williams's address should have been Wrexham Maelor Hospital, Croesnewydd Road, Wrexham, Clwyd LL13 7TD, UK.

\section{CALENDAR OF EVENTS}

Full details of events to be included should be sent to Maggie Butler, Technical Editor JCP, The Cedars, 36 Queen Street, Castle Hedingham, Essex CO9 3HA, UK; email:maggie.butler2@btopenworld.com

\section{UK NEQAS for Blood Coagulation Annual Scientific Meeting}

10-11 June 2003, Sheffield Hallam University, Sheffield, UK

Further details: Timothy AL Woods, UK NEQAS for Blood Coagulation, Rutledge Mews, 3 Southbourne Road, Sheffield S10 2QN, UK. (Tel: +44 (0)114 267 3300; Fax: +44 (0)114 267 3309; Email: talwoods@coageqa.demon. co.uk)

\section{Fourth International Symposium on Hormonal Carcinogenesis}

21-25 June 2003, Palau de la Musica, Valencia, Spain

Further details: Tandria Price/Dr Jonathan J Li, Department of Pharmacology, Toxicology and Therapeutics, Mail Stop 1018, University of Kansas Medical Center, 3901 Rainbow Blvd, Kansas City, KS 66160-7417, USA. (Tel: +1 913588 4744; Fax: +1 913588 4740; Email: tprice@kumc.edu; Website: http:/ www.kumc.edu/hormonecancers)

\section{UK NEQAS for Leucocyte Immunophenotyping Annual Scientific Meeting}

24-25 June 2003, Sheffield Hallam University, Sheffield, UK

Further details: June Pidd, UK NEQAS for Leucocyte Immunophenotyping, Rutledge Mews, 3 Southbourne Road, Sheffield S10 2QN, UK. (Tel: +44 (0)114 267 3600; Fax: +44 (0) 114 267 3601; Email: ukneqasli@btconnect.com)

\section{Practical Pulmonary Pathology}

22-25 July, 2003, Brompton Hospital, London, UK

Further details: Professor B Corrin, Brompton Hospital, London SW3 6NP, UK. (Fax: +44 (0) 207351 8293; Email: b.corrin@ic.ac.uk)

\section{ACP Management Course for Pathologists, 2003}

10-12 September 2003, Hardwick Hall Hotel, Sedgefield, County Durham, UK

Further details: Ms Valerie Wood, ACP Central Office, 189 Dyke Road, Hove, East Sussex, BN3 1TL, UK. (Tel +44 01273 775700; Fax +4401273 773303; Email: valerie@ pathologists.org.uk) 